\title{
Pharmacists' Insights and Behaviors in Preventing the Misuse of Topical Corticosteroids in Pakistan: A Mixed-Method Study
}

\author{
Sadia Shakeel ${ }^{1} @$, Shagufta Nesar ${ }^{2}$, Wajiha Iffat ${ }^{3}$, Hina Rehman ${ }^{4}$, Samreen Aziz ${ }^{5}$, Tayyaba Mumtaz ${ }^{6}$, \\ Hazrina Hadi ${ }^{7}{ }^{10}$ and Shazia Jamshed ${ }^{8, *}$
}

1 Department of Pharmacy Practice, Faculty of Pharmaceutical Sciences, Dow College of Pharmacy, Dow University of Health Sciences, Karachi 74200, Pakistan; sadia.shakeel@duhs.edu.pk

2 Jinnah College of Pharmacy, Sohail University, Karachi 74000, Pakistan; Shaguftausmani@sohailuniversity.edu.pk

3 Department of Pharmaceutics, Faculty of Pharmaceutical Sciences, Dow College of Pharmacy, Dow University of Health Sciences, Karachi 74200, Pakistan; wajiha.iffat@duhs.edu.pk

4 Institute of Pharmaceutical Sciences, Jinnah Sind Medical University, Karachi 75510, Pakistan; hina.rehman@jsmu.edu.pk

5 Department of Pharmacology, Faculty of Pharmacy, Jinnah University for Women, Karachi 74600, Pakistan; sam.aziz1987@outlook.com

6 Department of Pharmacognosy, Faculty of Pharmacy, Ziauddin University, Karachi 75000, Pakistan; tayyaba.faraz@zu.edu.pk

7 Department of Pharmaceutical Technology, Kulliyyah of Pharmacy, International Islamic University Malaysia, Kuantan 25200, Malaysia; hazrina@iium.edu.my

8 Department of Clinical Pharmacy and Practice, Faculty of Pharmacy, Universiti Sultan Zainal Abidin, Kuala 21300, Malaysia

check for

updates

Citation: Shakeel, S.; Nesar, S.; Iffat, W.; Rehman, H.; Aziz, S.; Mumtaz, T.; Hadi, H.; Jamshed, S. Pharmacists' Insights and Behaviors in Preventing the Misuse of Topical Corticosteroids in Pakistan: A Mixed-Method Study. Cosmetics 2021, 8, 72. https:// doi.org/10.3390/cosmetics8030072

Academic Editor: Enzo Berardesca

Received: 27 July 2021

Accepted: 6 August 2021

Published: 12 August 2021

Publisher's Note: MDPI stays neutral with regard to jurisdictional claims in published maps and institutional affiliations.

Copyright: (c) 2021 by the authors. Licensee MDPI, Basel, Switzerland. This article is an open access article distributed under the terms and conditions of the Creative Commons Attribution (CC BY) license (https:// creativecommons.org/licenses/by/ $4.0 /)$.
* Correspondence: shaziajamshed@unisza.edu.my

Abstract: Topical corticosteroids (TCs) misuse has become a common issue for healthcare professionals and patients, particularly in Pakistan, as no stringent laws or rules are prohibiting the selling of over-the-counter medicines. The present study was designed to examine pharmacists' insights and behaviors regarding TCs and their potential role in preventing the misuse of TCs in Pakistan. The study was a cross-sectional mixed-methods research design (phase 1, quantitative; and phase 2, qualitative) conducted from January to June 2021. The pharmacists working in various settings in Karachi were approached through different social media platforms. Data were collected through a web link of an online questionnaire with 30 closed-ended questions. Different statistical methods were employed for tabulating the quantitative data, while inductive thematic analysis was directed to classify themes from the qualitative data and to conclude findings. The mean cumulative knowledge score was $10.59 \pm 1.63$. The community pharmacists knew more about the available over-the-counter TCs $(p=0.041)$. The experienced pharmacists were more conversant than fresh pharmacists, regarding the mode of action ( $p=0.008)$, choice of TC potency $(p=0.001)$, and most common local and systemic adverse effects of TCs $(p=0.001)$. Overall, respondents had a favorable attitude, with more than $80 \%$ agreeing that pharmacists could ensure that important safety issues are communicated with patients, and assist considerably in avoiding TC misuse. Analysis of data has produced 7 themes, 10 sub-themes, and 30 categories. Major themes included: use and misuse of TCs, adverse drug events due to TCs, cosmeto-vigilance, patient education, referral to a physician, and future perspectives for preventing TC misuse. The respondents were well versed with the dilemma of TCs misuse, and they considered patient characteristics, free availability of TCs, and lack of physician-pharmacist coordination as the major reasons. The major barriers for patient education stated by nearly all the respondents were a lack of time and lack of material/information for counseling. They emphasized the need for stringent legal strategies and the enforcement of current drug-control regulations, so that TCs are not supplied without appropriate prescriptions. The present findings indicate that pharmacists had appropriate knowledge and a positive attitude towards their potential role in preventing the misuse of TCs. Further education and sensitization in areas of deprived knowledge will undoubtedly aid in the prevention of TCs misuse by the community. 
Keywords: pharmacists; mixed-method study; misuse; topical corticosteroids; cosmeto-vigilance; Pakistan

\section{Introduction}

The usefulness of topical corticosteroids (TCs), one of the most often used therapeutic class in dermatology, has become a two-edged sword, due to the rising incidence of misuse, which has devastating effects [1]. TCs are FDA-approved and intended for the treatment of pruritic and inflammatory dermatologic disorders. Psoriasis, eczema, acute radiation dermatitis, phimosis, limited regions of vitiligo, atopic dermatitis, lichen simplex chronicus, lichen planus, lichen sclerosis, and discoid lupus erythematosus are among the well-known indications [2,3]. They are useful in situations characterized by hyperproliferation, immunological, and inflammatory characteristics. Because of its quick impact in alleviating undesired signs and symptoms, TCs are one of the most often recommended medicines in dermatology [3]. Although, if they are not administered correctly or appropriate instructions are not provided to patients, TCs can be abused, causing adverse effects. Meanwhile, the misuse of TCs, particularly on the face, has grown, which has increased the occurrence of adverse effects [4]. When applied to the face, TCs cause unusual adverse effects, such as steroid-induced rosacea, itching, acneform eruptions, telangiectasia, dyspigmentation, hypertrichosis, tenia incognito, and atrophy [5]. A novel entity called a topical steroiddependent face has been established, which comprises exacerbated vascular symptoms, such as erythema and burning sensations that occur when TC treatment is discontinued [6].

The use of TCs with the appropriate strength, amount, and duration are critical to the treatment of both acute and chronic skin disorders. Low potency steroids, in general, are the safest medicines for long-term use, on broad surface areas, on the face, places with thinner skin, and on youths [7]. More powerful TC is beneficial only in cases of serious illness and on thicker skin on the palms and soles. Except in rare cases and for limited periods of time, high and ultra-high potency steroids should not be administered on the face, groin, axillae, or under occlusion. Misuse of TCs is well recognized, and has been investigated in several African and Asian nations [7,8]. Individuals are increasingly falling victim to the abuse of TCs as a result of social media, peer pressure, and unethical commercial methods [9]. With a low physician or specialist-to-patient ratio, patients are more susceptible to erroneous information and quackery. The most prevalent misuse and abuse of these products is long-term use as "fairness creams", that might lead to significant difficulties in the future [10]. When using TCs for an extended period, the skin may acquire permanent stretch marks (striae), bruising, discoloration, or thin spidery blood vessels (telangiectasias). Other skin diseases, such as acne, rosacea, and perioral dermatitis, may be triggered or worsened by TCs. These adverse effects are more common with more potent steroids, although they can be minimized by avoiding usage on the face [10].

In Pakistan, this problem has been exacerbated by improper prescriptions and the availability of all-powerful TCs as over-the-counter medicines [11]. Abuse of TCs as a fairness cream is common in our color-conscious society, where individuals are preoccupied with light skin for a variety of social reasons. TCs, similar to fairness creams, are widely available over-the-counter and are typically used as a depigmenting agent in conjunction with hydroquinone or mercury-based bleaching creams in disorders such as acne, melasma, freckles, and, in certain cases, simply to enhance the dark complexion. It is necessary to inform patients about the dangers of using TCs on their faces, as well as how to apply the TC and how long they should maintain treatment. TC prescriptions should include specific directions on where and how frequently to apply the preparation, as well as the body regions where usage should be avoided. Pharmacists should make certain that these instructions are included in the dispensing label. Prescribers should consider that patients may store unused or leftover TC skin preparations for some time after they are prescribed, and therefore forget the original indication or usage instructions. Hence, prescriptions in 
overly high numbers should be avoided [12]. Patients should be cautioned not to take more than the authorized dose; to stop its usage only under physician supervision; and not to share their TCs preparation with others, since doing so may result in hazardous application to inappropriate regions, such as the face, as well as lead to possibly improper treatment of undiagnosed skin diseases. Generally, the busy doctor may not have time to explain the risks of prolonged unsupervised use, and in such cases, the clinical pharmacist can be invaluable. Pharmacists are the patient's final point of contact before taking medicine, and could significantly contribute as educators, trailblazers, and advocates for the rational use of TCs in clinical practice to ensure that patients have access to safe and cost-effective medicines. The pharmacists could significantly contribute to medication safety, by ensuring proper medication prescribing with appropriate dose regimens and dosage forms; clarifying instructions on medicine use, including patient counseling; preventing potential medicine-disease, medicine-medicine, and medicine-food interactions; avoiding known and predictable ADRs; minimizing unnecessary treatment; and considering the cost of medicine [13].

Even though it is a frequent problem, no study has been conducted in Pakistan, to evaluate how pharmacists now rank their understanding of TCs. Hence, the present study was designed to examine pharmacists' insight and behaviors regarding TCs and their potential role in preventing the misuse of TCs in Pakistan. This research would aid in determining the pharmacist's concerns on the problems associated with the misuse of TCs for their safe, effective, and optimum advantages, and would subsequently aid in the development of a guideline or procedure for their logical and ethical use.

\section{Materials and Methods}

The current study was a mixed methods research design divided into two parts: a quantitative phase one, conducted through an online questionnaire; and a qualitative phase two, conducted through a semi-structured interview.

\subsection{Phase 1 (Quantitative Study)}

\subsubsection{Study Settings and Design}

The study was a cross-sectional electronic survey, conducted from January to June 2021. Data were collected through a web link of an online questionnaire with 30 closedended questions. The pharmacists were registered with the Pharmacy Council of Pakistan and were employed in community pharmacies, hospitals/clinics and academic settings in Karachi. They were approached through different social media platforms. Karachi is the biggest city in Pakistan and the twelfth largest city in the world. It is the capital of the Sindh province of Pakistan. To recruit community and hospital pharmacists, the telephone directory was used to get the landline numbers of several pharmacies and hospitals at random. The academic pharmacists were approached through official email addresses of their academic institutes.

\subsubsection{Sample Size Calculation}

The size of the study sample was calculated with the Raosoft sample size calculator (Raosoft Inc. ${ }^{\circledR}$, Seattle, WA, USA), by the formula as follows [14]:

$$
\begin{gathered}
\mathrm{x}=\mathrm{Z}\left(\frac{\mathrm{c}}{100}\right)^{2} \bullet r(100-\mathrm{r}) \\
\mathrm{n}=\frac{\mathrm{N} \bullet \mathrm{x}}{(\mathrm{N}-1) \mathrm{E}^{2}+\mathrm{x}} \\
\mathrm{E}=\operatorname{Sqrt}\left[\frac{(\mathrm{N}-\mathrm{n}) \mathrm{x}}{\mathrm{n}(\mathrm{N}-1)}\right]
\end{gathered}
$$


where $\mathrm{r}$ is the fraction of responses, $\mathrm{N}$ is the population size, $\mathrm{n}$ is the size of sample, $\mathrm{c}$ is the confidence level, $\mathrm{E}$ is the confidence interval, and $\mathrm{Z}(\mathrm{c} / 100)$ is the critical value intended for the confidence level.

\subsubsection{Study Instruments}

A comprehensive literature study was carried out, and several scientific search engines were used to find relevant papers for designing the questionnaire [13,15-17]. Following the completion of the initial questionnaire, the content and face validity of the questionnaire were assessed by specialists in pharmacy practice research, which included two community pharmacists and one academician. Modifications were made as per the experts' recommendations, to have an improved version of the questionnaire for the potential respondents.

Finally, for the final survey, a 30-item questionnaire with four sections was created. Section one consists of questions on the respondents' demographic information, such as gender, age, working organization, field, and experience. In order to assess the respondents' knowledge of TCs, 15 questions were posed in the second portion, including the role, mode of action, FDA-approved indications, adverse effects, dispensing protocol, and available over-the- counter TCs with options: "yes", or "no". Each correct answer received 1 point, with a possible total knowledge score of $0-15$; respondents with a score of $>10$ were considered to be adequately knowledgeable.

The third portion, with a total of five questions, focused on the attitude of respondents about their role in the rational use of TCs, using a 5-point Likert scale with scoring $1=$ strongly disagree to $5=$ strongly agree. The last segment of the questionnaire included 5 items, inquiring about the respondents' perceived causes of adverse drug events of TCs, and their main source of information. The reliability of the aforesaid tool was validated using Cronbach's alpha, the value was found to be 0.726 which is regarded within a satisfactory range, representing a good fit for internal consistency.

\subsubsection{Data Collection}

The questionnaire was designed as an online Google form with multiple sections, with the study's objectives and consent statement, "I consent to participate in this survey" stated on the first page, having an option of "Yes" in the response option box. Various social media channels, including "WhatsApp" and "Facebook Messenger", were utilized to administer the survey, depending on the respondents' preferences and convenience. To make participation easier, individuals were permitted to answer all of the questions by just clicking on a specified link. The link was also shared through email to the respondents whose email addresses were available.

The present study comprised of registered pharmacists who agreed to participate in the study. For data gathering, the snowball and convenient sampling approaches were utilized. The respondents were asked to distribute the questionnaire to their pharmacist colleagues at their respective work places. All information was gathered in the form of replies on a Google form (https:/ / docs.google.com/forms/, accessed on 12 June 2021), which were then converted into the data analysis software. The respondents who were community pharmacists (CPs) and completed the first part of the research were asked for their voluntary participation in the second study part by telephonic interviews, or by utilizing a variety of applications that were convenient for the respondents.

\subsubsection{Data Analysis}

The responses collected were transferred to the SPSS (Statistical Package for Social Sciences, Chicago, IL, USA, Version 25.0), where different statistical techniques were executed depending on the type of data. For calculating the frequencies and percentages, descriptive statistics were employed. The statistical association between dependent and independent variables were determined by the Pearson's chi-squared tests, considering a $p$-value $(<0.05)$ as statistically significant. 


\subsection{Phase 2 (Qualitative Study)}

\subsubsection{Study Instrument (Interview Guide)}

An interview guide, including themes, sub-themes, and questions (a total of 12 questions) with sub-sections was developed, depending on qualitative and explorative study designs. CPs were probed regarding their practice discussing safety issues of TCs with patients at the time of dispensing, their perceived barriers to patient counseling, and their views were obtained on TC misuse in Pakistan and how to curb the use of non-prescription TCs. Semi-structured interviews are effective instruments, offering numerous advantages, including the capacity to provide an in-depth examination of the respondents' awareness, practices, and intentions toward a certain topic [18].

\subsubsection{Data Collection}

In-depth interviews were directed with the CPs by telephonic interviews or by utilizing a variety of applications that were convenient for the respondents, following their informed consent. They were probed to determine their insights about the misuse of TCs and their suggestions for curbing the problem. Respondents were permitted to reply in English or Urdu (native language), according to their feasibility. Every interview took about 20-30 min. The telephonic interviews were recorded with permission and kept for further analysis.

\subsubsection{Analysis}

The data were subjected to a general inductive thematic analysis, which was followed by the development of themes. All of the recorded interviews were vigilantly played again, and the interpretations were precisely documented. The interviews were then transcribed verbatim from the audio recordings. The primary themes and sub-themes were determined, and certain codes were allocated to the retrieved useful data. The saturation point is the moment at which no themes or concepts are generated. It has been earlier suggested that qualitative studies need at least a sample size of 12 to reach data saturation. Hence, a sample of 14 was considered adequate for the qualitative analysis and scale of the present study.

\section{Results}

\subsection{Phase 1: Quantitative Study}

\subsubsection{Demographic Information}

Pharmacists from different pharmacies, academic institutes, and clinics/hospitals in Karachi were asked to participate in the current study. Twenty-one pharmacists did not express a willingness to participate after the first contact, while 26 pharmacists did not finish the survey and were therefore excluded. Finally, 329 completed questionnaires with a response rate of $65.8 \%$ were included. The respondents' average age was $31 \pm 6.1$ years (Table 1). The majority of respondents $274(83.2 \%)$ were female and $269(81.7 \%)$ respondents were working in a private work setting. Among them, $36(10.9 \%)$ were community pharmacists, $89(27.0 \%)$ were academic pharmacists, 57 (17.3\%) were hospital pharmacists, and $147(44.6 \%)$ were trainees. Trainee pharmacists were individuals who had recently graduated from pharmacy school, registered with the Pharmacy Council of Pakistan, and were working as interns in the hospital, community, or pharmaceutical industries. Forty-five percent had an experience of $1-5$ years. 
Table 1. Characteristics of study population.

\begin{tabular}{ccc}
\hline Baseline Characteristics & & Frequency (\%) \\
Mean \pm SD & Age (years) & \\
Male & Gender & $31 \pm 6.1$ \\
Female & & $55(16.7)$ \\
& Organization & $274(83.2)$ \\
Private & & $269(81.7)$ \\
Public sector & Field/Profession & $60(18.2)$ \\
& & $36(10.9)$ \\
Community Pharmacists & & $57(17.3)$ \\
Hospital Pharmacists & & $89(27.0)$ \\
Academicians & & $147(44.6)$ \\
Trainee $/$ Fresh Pharmacists & Experience & $107(32.5)$ \\
Less than 1 year & & $149(45.2)$ \\
1-5 years & & $27(8.2)$ \\
6-10 years & & $35(10.6)$ \\
1-15 years & & $11(3.3)$ \\
\hline
\end{tabular}

\subsubsection{Knowledge of Respondents about TCs}

The mean cumulative knowledge score was $10.59 \pm 1.63$. Table 2 revealed the respondents' knowledge towards TCs. Around $90 \%$ of the respondents knew the role of TCs in the treatment of numerous skin disorders. The community pharmacists were more familiar than pharmacists working in hospital or academic settings $(p=0.005)$. Almost $88 \%$ of respondents knew FDA-approved indications of TCs. More than $75 \%$ respondents knew that the TCs' mechanism of action is vast, comprising of anti-mitotic, anti-inflammatory, and immunosuppressive effects. More than $80 \%$ of respondents knew the available over-thecounter TCs. The community pharmacists knew more about the available over-the-counter TCs $(p=0.041)$. More than $75 \%$ of the respondents knew the mode of action, cutaneous adverse effects, and duration of use of TCs. The experienced pharmacists were more conversant than fresh pharmacists regarding the mode of action $(p=0.008)$, choice of TC potency $(p=0.001)$, and the most common local and systemic adverse effects of TCs $(p=0.001)$. The fresh pharmacists knew more about the application of TCs $(p=0.002)$. The respondents were more well-informed about the local adverse effects of TCs, as compared to systematic adverse effects. Figure 1 depicts the respondents' knowledge on local adverse drug reactions with the misuse of TCs. Acne $(81.4 \%)$, skin thinning $(78.6 \%)$, and perioral dermatitis $(75.6 \%)$ were the majorly reported adverse effects. Figure 2 depicts the respondents' knowledge on systemic adverse drug reactions with the misuse of TCs. Glaucoma and loss of vision (76.3\%) was the major reported systemic adverse drug reaction. The least knowledgeable area of respondents was the dispensing protocol of TCs, and the guidelines to prevent adverse effects when using TCs. 
Table 2. Respondents' knowledge towards TCs.

\begin{tabular}{|c|c|c|c|c|c|}
\hline Statement & Correct Answer & Gender & Organization & Field & Experience \\
\hline Role of TCs in treatment of numerous skin disorders & $295(89.6)$ & 0.037 & & 0.005 & \\
\hline FDA-approved indications of TCs & $289(87.8)$ & & 0.001 & & \\
\hline Mode of action of TCs & $257(78.1)$ & & 0.002 & 0.007 & 0.008 \\
\hline Choice of TCs potency & $236(71.7)$ & 0.031 & 0.006 & 0.009 & 0.001 \\
\hline Significant cutaneous adverse effects of TCs & $250(75.9)$ & & 0.001 & & 0.048 \\
\hline Most common local and systemic adverse effects of TCs & $228(69.3)$ & 0.025 & & & 0.001 \\
\hline Change of drug's potency due to delivery vehicle & $214(65.0)$ & & & & \\
\hline Application of TCs & $221(67.1)$ & & & & 0.002 \\
\hline Contraindications of TCs for bacterial infections & $209(63.5)$ & & 0.001 & & \\
\hline Monitoring of patients using TCs & $198(60.1)$ & 0.001 & & 0.001 & \\
\hline Guidelines to prevent adverse effects when using TCs & $185(56.2)$ & & & & \\
\hline Recommendations for patients using prescribed treatment & $202(61.3)$ & & & & 0.005 \\
\hline Dispensing protocol of TCs & $180(54.7)$ & & 0.04 & 0.002 & \\
\hline Duration of use & $253(76.8)$ & & & & \\
\hline Available over-the- counter TCs & $269(81.7)$ & & & 0.041 & \\
\hline
\end{tabular}

$p$ value less than 0.05 was considered as statistically significant using Pearson's chi-squared test.

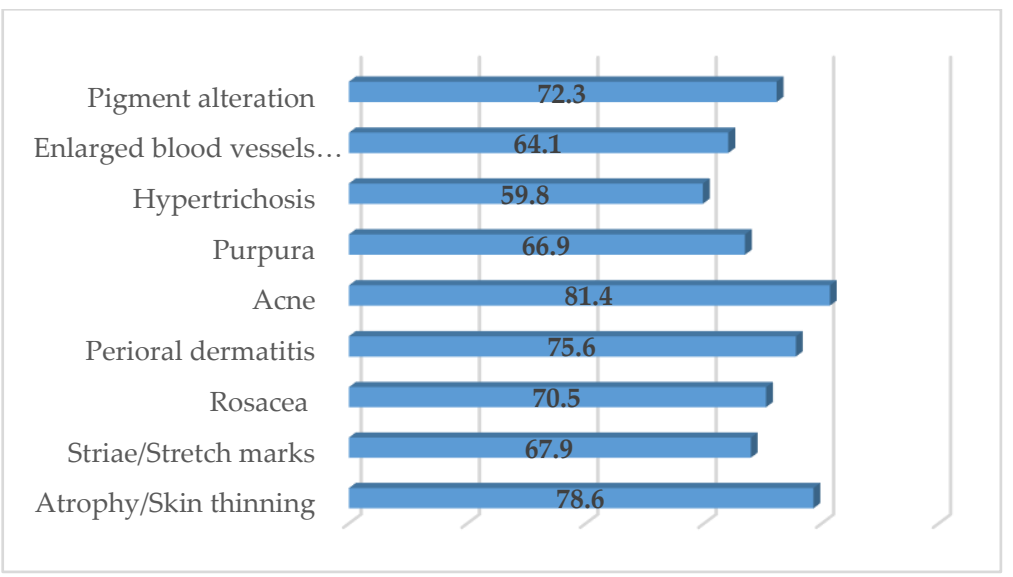

Figure 1. Respondents' knowledge on local adverse drug reactions with the misuse of TCs.

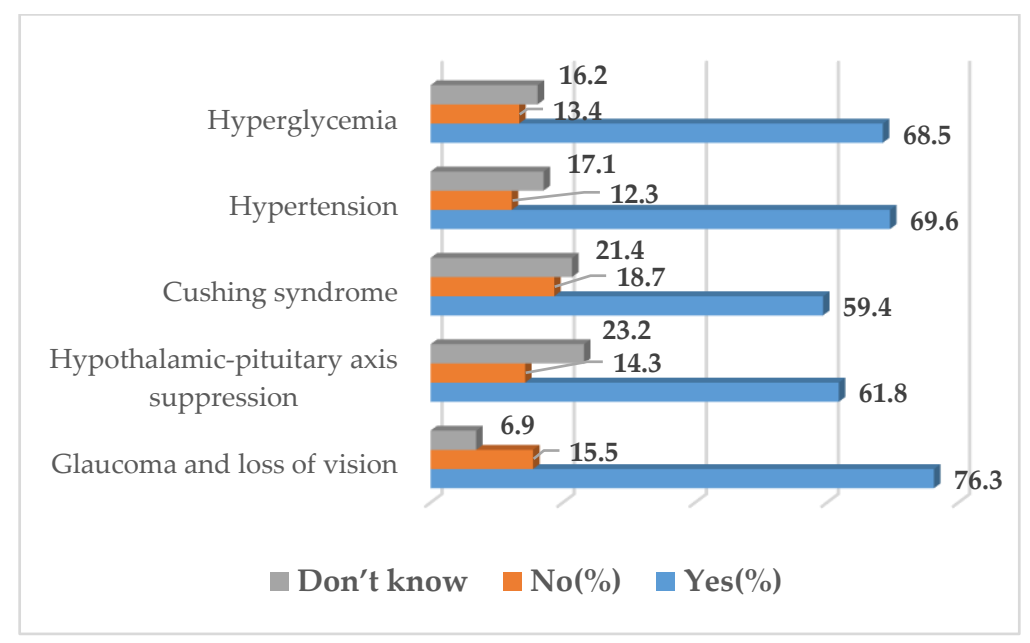

Figure 2. Respondents' knowledge on systemic adverse drug reactions with the misuse of TCs.

\subsubsection{Attitude of Respondents about Their Potential Role in Rational Use of TCs}

Table 3 displays respondents' attitudes on their potential role in the rational use of TCs. Overall, respondents had a favorable attitude, with more than $80 \%$ agreeing that pharmacists could ensure that important safety issues are communicated with patients, and assist considerably in avoiding TCs misuse. When compared to experienced pharmacists, the fresh pharmacists were more confident $(p=0.004)$ in significantly contributing to 
preventing TC misuse. The hospital pharmacists were more likely to agree that pharmacists could assist patients in the monitoring and avoidance of adverse effects associated with the use of TCs $(p=0.001)$. The community pharmacists were more enthusiastic to assist in reducing over-the-counter TC prescriptions $(p=0.006)$.

Table 3. Respondents' attitude towards their potential role in rational use of TCs.

\begin{tabular}{cccc}
\hline Statement & Strongly Agree/Agree & Neutral & Disagree/Strongly Disagree \\
\hline $\begin{array}{c}\text { Pharmacists could ensure that relevant safety problems } \\
\text { are discussed with patients. }\end{array}$ & $267(81.1)$ & $41(12.4)$ & $21(6.3)$ \\
$\begin{array}{c}\text { Pharmacist could contribute significantly in preventing } \\
\text { TCs misuse. }\end{array}$ & $279(84.8)$ & $36(10.9)$ & $14(4.2)$ \\
$\begin{array}{c}\text { Pharmacist could counsel and educate patient } \\
\text { regarding rational use of TCs }\end{array}$ & $245(74.4)$ & $47(14.2)$ & $37(11.2)$ \\
$\begin{array}{c}\text { Pharmacists could help patient in monitoring and } \\
\text { prevention of adverse effects of using TCs }\end{array}$ & $261(79.3)$ & $52(15.8)$ & $16(4.8)$ \\
$\begin{array}{c}\text { Pharmacist could help in limiting over-the-counter } \\
\text { prescriptions of TCs }\end{array}$ & $239(72.6)$ & $8(2.4)$ & $82(24.9)$ \\
\hline
\end{tabular}

3.1.4. Respondents' Perceived Reasons of Adverse Drug Events due to TCs in Community

The respondents' perceived major reasons of adverse drug events included using TCs for not applicable conditions $(27.2 \%)$, patient self-treatment $(20.9 \%)$, and patients not complying with treatment instructions $(18.1 \%)$. The respondents' major sources of TCs were drug information software/Internet (26\%), scientific papers/journals (21\%), and reference books (18\%) (Figure 3).

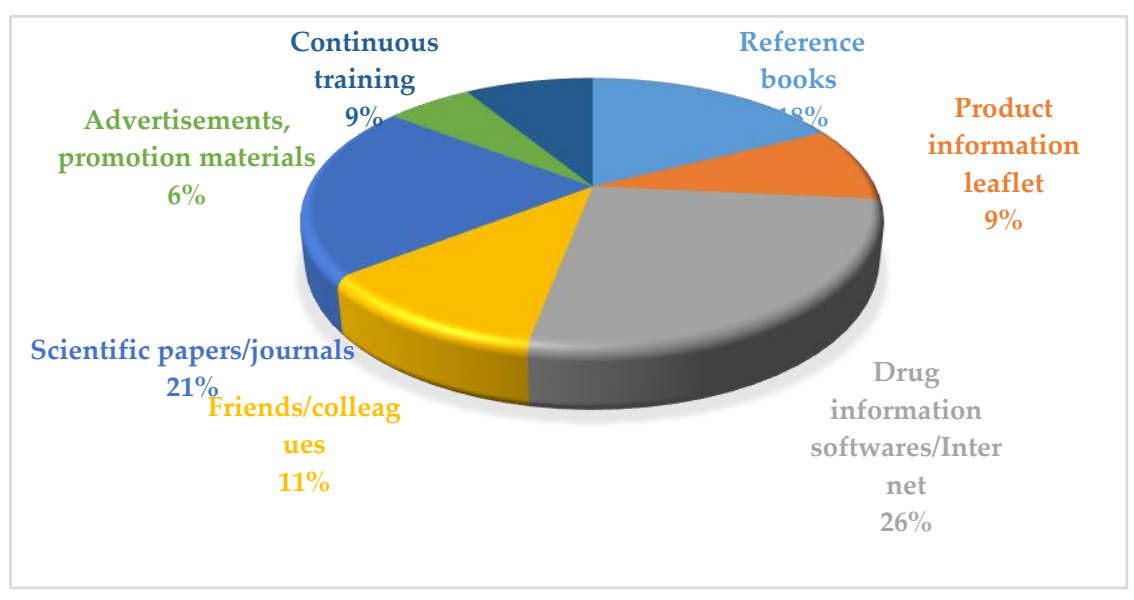

Figure 3. Respondents' preferred sources of information for TCs.

\subsection{Phase 2: Qualitative Study}

Overall, 14 community pharmacists (CPs) provided their consensus to participate in second phase of study. However, two of them did not attend the interview session and one of them did not complete the interview. Hence, comprehensive online interviews with a mean length of 25 min were conducted with 11 CPs. The mean age was between $25-38$ years and there were more males $(n=8)$. Eight respondents had $1-5$ years of experience, whereas three respondents had an experience of 10 years or more. Five respondents had specialization in their field as a Masters or $\mathrm{PhD}$, whereas six respondents were graduates. Analysis of data produced 7 themes, 10 sub-themes, and 30 categories (Table 4) 
Table 4. Detailed themes, sub-themes, and categories.

\begin{tabular}{|c|c|c|}
\hline Theme & Sub-Theme & Categories \\
\hline Use of TCs & $\begin{array}{l}\text { The most common type of skin } \\
\text { problems in the community }\end{array}$ & $\begin{array}{l}\text { Skin conditions such as rash and eczema are the most common skin } \\
\text { problems. Other skin conditions i.e., itching, dermatitis and psoriasis are } \\
\text { also common }\end{array}$ \\
\hline \multirow{9}{*}{ Misuse of TCs } & \multirow{5}{*}{ Patient characteristics } & Typically, people do not consult with a dermatologists \\
\hline & & Majority of patients do not finish the entire course of treatment \\
\hline & & Patients received recommendations from their relatives \\
\hline & & $\begin{array}{c}\text { Patients have their own ideas about how to treat themselves for skin } \\
\text { problems }\end{array}$ \\
\hline & & Patients use TCs as a general face cream or as a fairness cream \\
\hline & Access to TCs & $\begin{array}{c}\text { Over-the-counter availablity of high potency TCs without appropriate } \\
\text { prescriptions }\end{array}$ \\
\hline & & Consultation with a physician about a patient's medicines is quite \\
\hline & Physician pharmacist coordination & uncommon in Pakistan \\
\hline & & $\begin{array}{l}\text { Patients always rely only on the information a doctor has provided to them } \\
\text { Discontinue therapy and recommend patient to consult a dermatologist }\end{array}$ \\
\hline \multirow{3}{*}{$\begin{array}{l}\text { Adverse drug events due } \\
\text { to TCs }\end{array}$} & \multirow{3}{*}{$\begin{array}{l}\text { Response to patient complain of } \\
\text { adverse drug events }\end{array}$} & Notify to regional drug safety center \\
\hline & & Check if the patient has been using TCs as directed. \\
\hline & & Re-educate patient and recommend re-trial of the treatment \\
\hline \multirow[t]{3}{*}{ Cosmeto-vigilance } & \multirow{2}{*}{ Adverse effects reporting system } & Adverse effects reporting system need to well-structured \\
\hline & & $\begin{array}{l}\text { Current adverse effects reporting system is not beneficial to the public } \\
\text { Patient education has a significant role in reducing TCs abuse }\end{array}$ \\
\hline & Awareness & $\begin{array}{c}\text { Charts and pamphlets in local languages with pictorial illustrations might } \\
\text { be beneficial }\end{array}$ \\
\hline \multirow[t]{3}{*}{ Patient education } & \multirow{3}{*}{ Barriers } & Patients' unfavorable attitude for counseling \\
\hline & & $\begin{array}{c}\text { Doctors' dissatisfaction with pharmacist-assisted counseling } \\
\text { Lack of counseling material/information } \\
\text { Lack of time }\end{array}$ \\
\hline & & $\begin{array}{l}\text { Presume patients already know about TCs } \\
\text { When there is a need of making a correct clinical diagnosis }\end{array}$ \\
\hline \multirow{3}{*}{ Referral to a physician } & \multirow{3}{*}{$\begin{array}{c}\text { Situations in which to consider patient } \\
\text { referrals }\end{array}$} & Skin condition of moderate or greater severity \\
\hline & & Signs of skin infection \\
\hline & & $\begin{array}{l}\text { When the skin condition does not respond to therapy } \\
\text { Stringent drug-control policies so that TCs are not supplied without } \\
\text { appropriate prescriptions }\end{array}$ \\
\hline \multirow[t]{3}{*}{ Future perspectives } & \multirow{3}{*}{$\begin{array}{l}\text { Suggestions for preventing TCs } \\
\text { misuse }\end{array}$} & Improvements in packaging and specifying content \\
\hline & & Comprehensive information on product label \\
\hline & & More effective face-to-face counseling to patients \\
\hline
\end{tabular}

\subsubsection{Theme I: Common Skin Conditions}

The common skin conditions and misunderstandings concerning the use of TCs in patients were probed. Rashes and eczema were two of the most prevalent skin disorders. Other skin problems, such as itching, dermatitis, and psoriasis, were also commonly observed. The CPs agreed that the above skin conditions were most often reported, although two CPs had some experience with people who used TCs for cosmetic purpose.

"Although skin infections are not frequent, the majority of prescriptions were filled for eczema patients". (CP: 2)

"Skin problems like ... acne and dermatitis are quite frequent in the area." (CP: 5)

\subsubsection{Theme II: Misuse of TCs}

This shows that almost all CPs were well versed in the dilemma of TC misuse. They were probed on how to decrease the tendency of self-medication with TCs, and how to improve the appropriate use of TCs. The majority responded that most of the patients do not know about TCs, and at what time and in what manner to use them correctly.

"The majority of patients use TCs without dermatologist consultation; even when they were counseled, they sometimes do turn up for a refill of TCs prescription". (CP:2)

"The use of topical corticosteroids to lighten the skin is popular in Pakistan, particularly among young girls with lower socioeconomic level, however ... . Only few are aware of the possible adverse effects and significant health issues they might cause". (CP:3) 
The majority of respondents thought that pharmacist-physician collaboration for counseling on prescription medicines was critical in addressing the issue of TC misuse.

\subsubsection{Theme III: Response to Adverse Drug Events}

The respondents were probed on how to encounter a patient complaining of any ADR. When patients reported any adverse event to CPs, nearly all responders advised them to discontinue use of the TCs and seek medical treatment. Furthermore, after re-educating the patients, about three respondents said that they would confirm that the patients utilized the medicine as recommended. Only one respondent reported adverse events to a regional drug safety center.

"Reviewing how patients are using their medications might lead to recommendations for changes in medication or dosing that improve patient safety and drug adherence". (CP: 5)

\subsubsection{Theme IV: Cosmeto-Vigilance}

The majority of the respondents agreed that the ADR reporting system in Pakistan is not appropriate; however, they were optimistic about their role in the adverse effects reporting system. They all agreed that ADR reporting is critical and that all healthcare providers should report ADR in their everyday activities.

"It is a need of time to develop an effective adverse effects reporting system in accordance with international standards in Pakistan and not only pharmacists but all healthcare professionals must be trained on reporting ADRs". (CP: 10)

\subsubsection{Theme V: Patient Education}

The CPs' responses regarding the ways to increase the patient education and awareness about the rational use of TCs were recorded. The major barriers stated by nearly all of the respondents were lack of time and lack of material/information for counseling. Two respondents stated the patients' unfavorable attitude for counseling.

"I constantly attempt to provide counseling on when, how, and why TCs should be taken, as well as their detrimental effects". (CP:4)

"If a patient receives TCs without consulting with a dermatologist, there is a risk of medication error". (CP:3)

"Poor education is a significant obstacle to counseling in our country that is difficult to overcome but may be decreased by establishing special counseling procedures for patients with low education, such as the use of pictograms". (CP: 4)

\subsubsection{Theme VI: Referral to a Physician}

The CPs were inquired about the situations in which to consider patient referrals, since there is an unexplained variance in the general practice of referral rates, necessitating to probe the CPs' views and expectations during the referral process.

"There are times when it is obvious that we want the services of an expert dermatologists. For example, we have a patient who is having symptoms of severe skin infections. Or even unusual, but with risk factors, so we tell ourselves that we can't afford to waste time and must rule out a cause...." (CP: 6)

\subsubsection{Theme VII: Future Perspectives}

TC misuse has become a common issue for healthcare professionals and patients, particularly in Pakistan, as there are no stringent laws or rules prohibiting the selling of over-the-counter medicines. The respondents were asked to provide suggestions for preventing TC misuse.

"Sometimes our guidance is forgotten rapidly, and the label of the product is the only guideline that remains with the patient. Pharmaceutical companies should be obliged 
to assure appropriate labeling of TC products, which should include inserts with clear "fingertip unit" instructions, preferably with graphics and a chart showing the amount necessary for particular regions of the body. This will significantly aid in the optimal and safe usage of TC". (CP: 4)

"There is a need of stringent legal strategies and the enforcement of current drug-control regulations so that TCs are not supplied without appropriate prescriptions". (CP: 2)

\section{Discussion}

Pakistan is the world's fifth most populated country, with an ever-increasing demand for healthcare [19]. This, in turn, increases the strain on healthcare and necessitates a larger and more skilled staff to meet the rising requirements of the healthcare system. The pharmacy profession is all about providing comprehensive care to patients, as well as achieving, maintaining, and regaining optimal health [20]. To the best of our understanding, this is the first study employing a mixed method approach conducted on pharmacists' knowledge, attitudes, and behaviors related to TC misuse in the Pakistani community. The present study revealed that the mean cumulative knowledge score of respondents towards TCs was $10.59 \pm 1.63$. More than $80 \%$ of respondents were familiar with the available over-the-counter TCs. More than $75 \%$ of respondents knew that the TCs' mechanism of action is vast, comprising of anti-mitotic, anti-inflammatory, and immunosuppressive effects. The majority of the respondents knew that TCs are FDA-approved, and have a key role in the treatment of pruritic and inflammatory presentations of dermatologic conditions. The respondents knew that the efficacy of TCs is dependent on obtaining a correct diagnosis, selecting the proper medication, choosing the suitable vehicle and strength, and the accurate frequency of application. Their degree of knowledge was positively associated with their practice, but it also increased sensitivity to perceived barriers, which might be adversely associated with their practice. Similar findings were reported by another study, in which the general understanding of TCs was well understood by community pharmacists [21]. Because of their higher surface area to body weight ratio, very powerful TCs can be absorbed effectively enough in children and babies, resulting in systemic adverse effects [22]. In the present study, while most respondents were aware of the local adverse effects of TCs, fewer than half were aware of their potential systemic adverse effects. Evidence suggests that pharmacists help educate patients about the use of TCs. However, pharmacists must grasp the subject before providing guidance and expertise to patients and caregivers. It is well documented that pharmacists' misinformation has a significant influence on the general public's views of TCs [17]. In the present study, the least conversant area of respondents was the dispensing protocol of TCs and the guidelines to prevent adverse effects when using TCs. Other research found that pharmacists had gaps in their knowledge of the use of TCs in atopic eczema, despite having a strong grasp of the use of emollients in the same condition [23].

TCs have a significant role in clinical dermatology. However, the majority of Asian societies as well as some of those in the western world are obsessed with fairness and light skin, and are quite color-conscious due to a cultural belief that light skin is more beautiful than dark. This tendency leads to the usage of any agent that gratifies this obsession, including one that is harmful when taken over a protracted length of time [24]. The most commonly used tool for such objectives is TCs, which may be used alone, in combination with various fairness creams, or mixed with skin lightening treatments and bleaching chemicals. This double-edged sword has the potential to produce an epidemic of acne, hirsutism, rosacea, telangiectasia, facial wrinkling, and steroid dependence among its users. OTC availability, promotion by non-medical people, and a lack of any accountability for such medications have all contributed to Pakistanis being victims of severe adverse effects [8]. The present findings revealed that respondents were well versed in the dilemma of TC misuse. They had a favorable attitude, with more than $80 \%$ agreeing that pharmacists could ensure that important safety issues are communicated with patients and assist considerably in avoiding TC misuse. However, in another study, the respondents were 
less likely to give patient counseling on the safety of TCs, probably due to a lack of understanding in this area. The respondents in our study opined that certain TCs are accessible without a prescription, for individuals who have not visited a doctor in a long time to self-medicate. In such circumstances, the respondents showed a willingness to provide patient counseling on the use of TCs.

Several studies have revealed that individuals are not adequately educated on TCs and their use by their healthcare practitioners [25-27]. Similarly, the present findings indicate the respondents' agreement that a lack of patient education on TC usage has a detrimental influence on the therapy that patients receive. Patients' commitment to therapy is hampered by unfounded worries about TCs, which may have an impact on treatment success. Such concerns may be alleviated with good patient education on TCs, particularly if aimed towards altering basic attitudes about TCs. This is a role that healthcare practitioners, especially community pharmacists, may play to aid the optimal and safe usage of TC.

The respondents in the current study emphasized the need of appropriate labeling of TC products. They opined that dermatology prescribing might be viewed as inaccurate, since neither the patient nor the physician is always sure how much topical medication to administer. Patients, on the other hand, rely largely on their prescribers' instructions and the product documentation to utilize TCs appropriately. This problem is exacerbated by the fact that most TC medications are distributed with labeling that typically states to 'use as advised' and 'apply thinly'. This creates issues, since such directions are subjective and imprecise, but they are also risky if not followed [28]. The respondents in the present study opined that the pharmaceutical companies should include inserts with clear "fingertip unit" instructions, preferably with pictorial illustrations showing the amount necessary for particular regions of the body.

Another major focus of our study was to gain pharmacists' insight towards ADR reporting and cosmeto-vigilance. Doctors of all specialties, mostly dermatologists, prescribe topical treatments which have varying concentrations of TCs, in spite of that the misuse of such medications are common in countries like Pakistan, where all medications are accessible without appropriate prescription. Several adverse effects related to TC misuse are directly associated with the potency of TCs, and usually become more widespread with the use of high potency TCs [29]. The respondents were probed on how to encounter a patient complaining of any ADR, and their inclination to report the ADR. The findings of our study are parallel to the findings of other studies conducted on pharmacists, revealing the respondents' readiness to report ADRs, as they saw it as their professional obligation. They all agreed that ADR reporting is critical, and that all healthcare providers should report ADR in their everyday activities. The majority of the respondents agreed that the ADR reporting system in Pakistan is not appropriate; although, they were optimistic about their role in the adverse effects reporting system. The role of a clinical pharmacist in directing the system on the correct track has already been explored and recorded. They can also provide appropriate counsel when an unfavorable incident is seen [13]. It is the right time for dermatologists to recognize the value of clinical pharmacists, and begin involving them more meaningfully in patient care. This relieves the clinician's workload, allowing him to devote more time to patient care. The major barriers stated by nearly all the respondents in the present study were lack of time and lack of material/information for counseling. Two respondents stated the patients' unfavorable attitude toward counseling. Negative attitudes of doctors were also mentioned as a barrier to patient counseling. It has been reported that unpleasant interactions between pharmacists and physicians develop when pharmacists try to expand their involvement in pharmaceutical treatment [30]. Another study reported negative patient perception of TCs as one of the barriers [17]. In the present study, the drug information software/Internet was ranked first as the respondents' major sources for TCs, followed by scientific papers/journals, and reference books. Another study supports the present findings [21].

TC misuse has a substantial influence on dermatological practice, since it accounts for a significant number of dermatology clinic visits [31]. To solve this hydra-headed challenge, 
multi-dimensional actions, including educational, managerial, and legal approaches are required. The most essential methods to increase awareness about the hazards of TC misuse are probably education of the general public through media programs and the implementation of continuing medical education programs for medical, paramedical staff, and pharmacists. In addition, legal ways should include the enforcement of current legislation that prohibits the sale of potent TCs without a competent doctor's prescription.

A strength of the study is the fact that we employed a mixed method approach, in which the second phase of the study was partly generated from the first. The qualitative study assisted in developing topics to test in the questionnaire, but outcomes from the surveys may also be explained using insights gained from the interviews. In addition, the study gathered anonymous replies from pharmacists of various ages, years of practice, and genders who completed and returned the questionnaire. We recognize that this study has certain limitations. In the current study, the pharmacists were surveyed in a precise period in Karachi. The outcomes may not be sweeping to all pharmacists in Pakistan. In addition, the outcomes of the study were established on self-reported information that might be influenced by the reliability and recall of the aptitude of the respondents.

\section{Conclusions}

The present findings indicate that pharmacists had appropriate knowledge of TCs and a positive attitude towards their potential role in preventing the misuse of TCs. The majority agreed on several aspects, including the fact that the topical medications are frequently utilized in situations when they should not be used, resulting in a variety of adverse consequences, the necessity of the pharmacist's role in avoiding TCs misuse, and the need to conform to dispensing guidelines. Further educating and sensitizing them in areas of deprived knowledge will undoubtedly aid in the prevention of TC misuse by the community.

Author Contributions: Conceptualization, S.S. and W.I.; methodology, S.S. and S.N.; software, S.S.; validation, S.S. and W.I.; formal analysis, S.S. and S.N.; investigation, S.S., S.N. and W.I.; resources, S.N., H.R., S.A. and T.M.; data curation, H.R., S.A. and T.M.; writing-original draft preparation, S.S.; writing-review and editing, H.H. and S.J.; visualization, S.S. and W.I.; supervision, H.H. and S.J.; project administration, S.S. and W.I. All authors have read and agreed to the published version of the manuscript.

Funding: This research received no external funding.

Institutional Review Board Statement: The study was conducted agreeing with the recommendations of the Declaration of Helsinki and approved by the Ethical Review Committee of Sohail University, Karachi, Pakistan with the protocol \# 000111/21.

Informed Consent Statement: Written informed consent was obtained from the respondents for their voluntary participation.

Conflicts of Interest: The authors declare no conflict of interest.

\section{References}

1. Silverberg, J.I.; Toth, D.; Bieber, T.; Alexis, A.F.; Elewski, B.E.; Pink, A.E.; Hijnen, D.; Jensen, T.N.; Bang, B.; Olsen, C.K.; et al. Tralokinumab plus topical corticosteroids for the treatment of moderate-to-severe atopic dermatitis: Results from the double-blind, randomized, multicentre, placebo-controlled phase III ECZTRA 3 trial. Br. J. Dermatol. 2021, 184, 450-463. [CrossRef] [PubMed]

2. Meena, S.; Gupta, L.K.; Khare, A.K.; Balai, M.; Mittal, A.; Mehta, S.; Bhatri, G. Topical corticosteroids abuse: A clinical study of cutaneous adverse effects. Indian J. Dermatol. 2017, 62, 675. [PubMed]

3. Das, A.; Panda, S. Use of topical corticosteroids in dermatology: An evidence-based approach. Indian J. Dermatol. 2017, 62, 237. [PubMed]

4. Kumar, S.; Goyal, A.; Gupta, Y.K. Abuse of topical corticosteroids in India: Concerns and the way forward. J. Pharmacol. Pharmacother. 2016, 7, 1 .

5. Song, S.Y.; Jung, S.-Y.; Kim, E. Steroid phobia among general users of topical steroids: A cross-sectional nationwide survey. J. Dermatol. Treat. 2019, 30, 245-250. [CrossRef] 
6. Chiricozzi, A.; Comberiati, P.; D’Auria, E.; Zuccotti, G.; Peroni, D.G. Topical corticosteroids for pediatric atopic dermatitis: Thoughtful tips for practice. Pharmacol. Res. 2020, 158, 104878. [CrossRef]

7. Hawsawi, K.; Alaauldeen, S.; Albarnawi, N.; Mashrai, H.; Alosaimi, R.; Alsufyani, H. Prevalence of misuse of topical corticosteroids among populations in western region of Saudi Arabia. Int. J. Adv. Res. 2017, 5, 297-307. [CrossRef]

8. Tsegaye, M.; Shimels, T.; Bilal, A.I. Prevalence of topical corticosteroids related adverse drug events and associated factors in selected community pharmacies and cosmetic shops of Addis Ababa, Ethiopia. Sudan J. Med. Sci. 2018, 13, 62-77.

9. Manchanda, K.; Mohanty, S.; Rohatgi, P.C. Misuse of topical corticosteroids over face: A clinical study. Indian Dermatol. Online J. 2017, 8, 186. [CrossRef]

10. Sharma, R.; Abrol, S.; Wani, M. Misuse of topical corticosteroids on facial skin. A study of 200 patients. J. Dermatol. Case Rep. 2017, 11, 5. [CrossRef]

11. Fasih, S.; Arif, A.B.; Amar, A.; ul Haque, M.; Hameed, F.; Iqbal, J. Misuse of topical corticosteroids on facial skin. Pak. J. Physiol. 2020, 16, 11-13.

12. Sendrasoa, F.A.; Ranaivo, I.M.; Andrianarison, M.; Raharolahy, O.; Razanakoto, N.H.; Ramarozatovo, L.S.; Rapelanoro Rabenja, F. Misuse of topical corticosteroids for cosmetic purpose in Antananarivo, Madagascar. BioMed. Res. Int. 2017, $2017,9637083$. [CrossRef]

13. Ashique, K.; Chandrasekhar, D. Role of clinical pharmacist in cosmeto-vigilance of misuse and abuse of topical corticosteroids. Indian J. Dermatol. 2017, 62, 213-214. [CrossRef]

14. Omair, A. Sample size estimation and sampling techniques for selecting a representative sample. J. Health Spec. 2014, 2, 142. [CrossRef]

15. D'Souza, P.; Rathi, S.K. Rational Use of Topical Corticosteroids. In A Treatise on Topical Corticosteroids in Dermatology; Springer Nature Switzerland AG: Cham, Switzerland, 2018; pp. 117-127.

16. Ashique, K.T.; Kaliyadan, F.; Mohan, S.; Vijayan, S.; Chandrasekhar, D. Knowledge, attitudes and behavior regarding topical corticosteroids in a sample of pharmacy students: A cross sectional survey. Indian Dermatol. Online J. 2018, 9, 432.

17. Kang, M.J.; Park, J.H.; Park, S.; Kim, N.G.; Kim, E.Y.; Yu, Y.M.; Kim, D.Y.; Lee, J.Y.; Shin, W.G.; Choi, S.A. Community pharmacists' knowledge, perceptions, and practices about topical corticosteroid counseling: A real-world cross-sectional survey and focus group discussions in Korea. PLoS ONE 2020, 15, e0236797. [CrossRef]

18. Vazquez-Lago, J.; Gonzalez-Gonzalez, C.; Zapata-Cachafeiro, M.; Lopez-Vazquez, P.; Taracido, M.; López, A.; Figueiras, A. Knowledge, attitudes, perceptions and habits towards antibiotics dispensed without medical prescription: A qualitative study of Spanish pharmacists. BMJ Open 2017, 7, e015674. [CrossRef]

19. Javed, S.A.; Liu, S.; Mahmoudi, A.; Nawaz, M. Patients' satisfaction and public and private sectors' health care service quality in Pakistan: Application of grey decision analysis approaches. Int. J. Health Plan. Manag. 2019, 34, e168-e182. [CrossRef]

20. Farrugia, L.L.; Lee, A.; Fischer, G.; Blaszczynski, A.; Carter, S.R.; Smith, S.D. Evaluation of the influence of pharmacists and GPs on patient perceptions of long-term topical corticosteroid use. J. Dermatol. Treat. 2017, 28, 112-118. [CrossRef]

21. Smith, S.D.; Lee, A.; Blaszczynski, A.; Fischer, G. Pharmacists' knowledge about use of topical corticosteroids in atopic dermatitis: Pre and post continuing professional development education. Australas. J. Dermatol. 2016, 57, 199-204. [CrossRef]

22. Smith, S.D.; Farrugia, L.L.; Harris, V.; Lee, A.; Carter, S.R.; Blaszczynski, A.; Fischer, G. Evaluation of the influence of family and friends, and the Internet on patient perceptions of long-term topical corticosteroid use. J. Dermatol. Treat. 2017, 28, 642-646. [CrossRef]

23. Lau, W.M.; Donyai, P. Knowledge, attitude and advice-giving behaviour of community pharmacists regarding topical corticosteroids. Pharmacy 2017, 5, 41. [CrossRef]

24. Shaheen, S.; Shahbaz, A.; Maqbool, N.; Shaheen, J.A. Use of topical corticosteroids and mixed creams over the face among female medical students of Quaid-e-Azam Medical College, Bahawalpur. J. Pak. Assoc. Dermatol. 2020, 30, 143-150.

25. Satheesh, G.; Puthean, S.; David, E. The Unattended Crisis of Topical Steroid Misuse: A Review. SM J. Pharmac. Ther. 2018, 4, 1020.

26. Majed, D.; Alnujaidi, M.; Almohammadi, N.; Kokandi, A.A. Use of topical steroids on the face among university students in Saudi Arabia. Biomed. Res. 2018, 29, 2786-2789. [CrossRef]

27. Dhanalakshmi, K.; Sudarvizhi, A.; Jennifer, G. Factors influencing the use of topical steroid based medications in tinea infection in a tertiary care centre, Tamilnadu. J. Pak. Assoc. Dermatol. 2020, 30, 636-642.

28. Hanif, M.M.; Shahid, M.; Makki, M. Frequency of steroid induced acne among acne patients. Age 2018, 10, 34.

29. Pandhi, D.; Kataria, V. Topical Corticosteroids. In Comprehensive Textbook on Vitiligo; CRC Press: Boca Raton, FL, USA, 2020; pp. 107-114.

30. Smith, S.D.; Harris, V.; Lee, A.; Blaszczynski, A.; Fischer, G. General practitioners' knowledge about use of topical corticosteroids in paediatric atopic dermatitis in Australia. Aust. Fam. Physician 2017, 46, 335-340. [PubMed]

31. Smith, S.D.; Lee, A.; Blaszczynski, A.; Fischer, G. Attitudes of A ustralian dermatologists to the use and safety of topical corticosteroids in paediatric atopic dermatitis. Australas. J. Dermatol. 2016, 57, 278-283. [CrossRef] [PubMed] 